\title{
Comparing the Tribological Properties of Chloride-Based and Tetra Fluoroborate-Based Ionic Liquids
}

\author{
Shirke Saurabh Dyaneshwar ${ }^{1}$, Shah Aditya Manoj ${ }^{1}$, Dulange Amit Gangadhar ${ }^{1}$, Kamlesh Rudreshwar Balinge ${ }^{2}$, Anil \\ Payyappalli Mana $^{1 *}$, Pundlik Rambhau Bhagat ${ }^{3}$ \\ ${ }^{1}$ School of Mechanical Engineering, Vellore Institute of Technology, Vellore 632014, India \\ ${ }^{2}$ Department of Science and Humanities, Saveetha School of Engineering, Chennai 602107, India \\ ${ }^{3}$ Department of Chemistry, School of Advanced Sciences, Vellore Institute of Technology, Vellore 632014, India
}

Corresponding Author Email: pmanil@vit.ac.in

https://doi.org/10.18280/acsm.430507

Received: 16 July 2019

Accepted: 27 August 2019

\section{Keywords:}

tribological properties, friction, lubricant, ionic liquids, surface characterization

\begin{abstract}
Methyl-imidazolium based ionic liquids have good tribological properties, because of their ability to form a chemically reacted film on the surface. This paper mainly compares the tribological properties of two ionic liquids, namely, the chloride-based imidazolium ionic liquid (IL1) and the tetrafluoroborate-based methyl-imidazolium ionic liquid (IL2). The two ionic liquids were synthesized in the lab and blended with mineral base oil at various proportions, i.e. $0.5 \%, 1 \%$ and $1.5 \%$ by weight. The tribological properties of the oil samples were tested for $1 \mathrm{hr}$ on a reciprocating wear testing machine using a ball-on-flat configuration. The flat is made of hardened AISI 52100 steel, while the bearing ball made of the same material serves as the counter facing surface. The results show that IL2 exhibited a nearly $40 \%$ smaller friction coefficient than IL1 at $100^{\circ} \mathrm{C}$; the IL1 was found to corrode the steel specimens at $100^{\circ} \mathrm{C}$; the AFM images showed the formation of chemically reacted tribofilms on the surface of samples tested with IL2; SEM and EDS results proved the presence of chlorine, boron, and fluorine on the respective wear tracks.
\end{abstract}

\section{INTRODUCTION}

The limitations of conventional lubricants are that they are suitable for one particular pair of materials. It may not work for another pair. Also, the various kinds of additives added in fully formulated oils may not be compatible with all types of materials [1]. Whereas ionic liquids are not so when added as additives. Ionic liquids are positively and negatively charged ions of compounds. They are neither acidic nor basic. Most of these compounds are in the liquid state. However semi-solid ionic liquids also exist. The major characteristics of ionic liquids are low volatility, low melting point, non-flammability, thermal stability and good thermal conductivity. The major disadvantage of using phosphonium and tungstate based ILs are that they corrode the metal at high concentration so the amount of the ionic liquid in lubricating oil should be controlled in such a way that they do not cause any harm to the surfaces in contact [1].

The first article that brought about the use of ionic liquids as lubricants was published in the year 1961 [2]. A mixed salt of $\mathrm{LiF}, \mathrm{BeF}_{2}$, and UF4 melted at $460{ }^{\circ} \mathrm{C}$ was tested at 650 $815^{\circ} \mathrm{C}$. However, its use was reported as a nonconventional class of solvents [3-4]. Room temperature ionic liquids were still not explored as lubricants until the year 2001. In 2001, Ye et al. [5], reported that alkyl imidazolium tetrafluoroborates at room temperatures have good antiwear properties and exhibited a low coefficient of friction when tested with various material pairs such as steel/steel, steel/ aluminum etc. [5]. Imidazolium-based ionic liquids have been the most investigated for their lubricating properties [5-12]. The superior tribological performance of ionic liquids is attributed to the dipolar structure and their ability in adsorbing on to the surface of the materials and subsequent formation of an antiwear film [5]. Even though some of the hydrophilic ionic liquids have been proved to be corrosive against steel [13-19], ionic liquids can be subjected to very severe load conditions $[5,7]$ and exhibit very high thermal decomposition temperatures [7]. A comparative study was reported between tribological properties of imidazolium-based ionic liquids under steadily advancing loads in alloys that were applied with ionic liquids versus uncoated alloys. The results proved that the alloys not coated with ILs did not show good wear resistance. The SEM analysis also showed that there was the formation of a phosphate-based reaction film which reduced the friction [9]. Ionic liquids applied with two layers on a silicon substrate; among them, one layer acting as an anchor layer proved to have better tribological properties than applied as a single layer [10]. Furthermore, carbon chain length on the imidazole ring of certain halogen-free ionic liquids was reported to influence the tribological properties when used in steel-copper contacts [11]. Load carrying capacity has been proved to be much better than conventional ZDDP based lubricants [7]. Environmental friendly ionic liquids that are free from halogens, phosphorous and sulfur have also been proved to have good tribological properties. These bis borate anion based and imidazolium/ammonium cation ionic liquids exhibited high viscosity, hydrophobicity and good miscibility with base stocks [20]. But Pyridinium based ionic liquids with methyl sulfate anions have been found to be highly corrosive. Dicationic structures exhibited better performance compared to mono cationic structures [21].

Much interest was observed among the researchers in 
phosphonium based ionic liquids in the last decade [22-31]. Good thermal stability and non-corrosiveness along with friction reduction properties were demonstrated by phosphonium based ionic liquids. Oil solubility of these ionic liquids was much influenced by the alkyl chain length and hydrogen bonding between the anion and cation [22]. Thicker tribofilms were observed in the case of ceramic-steel contacts compared to steel-steel contacts when tested with phosphonium based ILs. Higher thickness is attributed to higher contact pressures due to small contact zones [23]. While ZDDP failed to prevent scuffing at the early stages of the interaction, Trihexyl tetradecyl phosphonium bis (2ethylhexyl) phosphate IL showed much satisfactory boundary lubrication properties with much lower wear rates. This has been attributed to the formation of a two-layer structured tribofilm on the surface [24]. DLC surfaces gave the higher coefficient of friction when compared with boride coatings while interacting in the presence of IL-based lubricants. Wear debris digestion has been reported to be responsible for the formation of the wear resistant tribofilm [25]. Better tribological properties were achieved when used engine oils containing depleted additives were added with phosphonium based ILs. Used engine oils can get enhanced service life with the proper addition of ILs [26]. Few researchers reported that better tribological properties and high-temperature performance were exhibited by phosphonium based ILs, especially the two phosphorous species when blended with base oil and polyol esters [27-29]. Zhu Lili et al. [29] used ionic liquids which can be easily mixed with oil. These liquids showed excellent friction reduction and also the SEM analysis confirmed the formation of phosphate and sulfate-based surface films. Good synergy was reported between phosphonium cation ILs and oxide nanoparticles when mixed together resulting in a substantial decrease in friction and wear [30]. Recently, the compatibility of room temperature ILs such as phosphonium and imidazolium with avocado oil was tested and found its effectiveness in reducing friction and wear [31]. Gearbox oils showed a different behavior when blended with ILs. Quality of the oil deteriorated over a period of time when the test severity increased. Tribological properties did not improve even with the addition of ILs [32]. Anil and Rajamohan [33] varied the surface texture of the base metal and used ZDDP as an additive and its effectiveness was tested. The results showed that if pressure (perpendicular to contact) is increased the wear also increases. Nano-Tribology tests were conducted by Tiago et al. [34] on methyl-pyridinium based ionic liquids. The results of the experiment showed that the place where a methyl group is located on the pyridine ring affects the film formation and leads to varying coefficient of friction. Inés et al. [35] used phosphate-contingent ionic liquids as additives in the lubricating oil. Phosphate-based ionic liquid showed less wear and friction than the others. Studies by Jian et al. [36] showed that polymer ionic liquids have the capacity to lubricate steel-steel contacts at high load. These ionic liquids are more superior than existing lubricant as they have the ability to sustain high temperature and high sliding velocity. Guowei et al. [37] used guanidinium ILs which proved to be a better lubricant than the esters. At high temperatures of around $300{ }^{\circ} \mathrm{C}$, these liquids are stable and have exemplary anti-wear properties. Huaping et al. [38] studied the addition of amine-based ionic liquid to the lubricating oil. It showed remarkable results as compared to base oil. In this research, nano-intercalates were used for improving the anti-wear properties of the base oil.
Ionic liquids used in the past have shown significant evidence of decreasing the friction and wear between two sliding surfaces. Various phosphonium and tungstate based liquids have been instrumental in decreasing the friction to a greater extent. However, the literature shows that most of the research on the methyl-imidazolium ionic liquid is conducted at one particular temperature and a comprehensive study on the effect of varying the temperature is lacking. The present work is focused on studying the influence of temperature on the tribological behavior of two lab-synthesized ILs when blended with mineral base oil at various concentrations.

\section{METHODOLOGY}

\subsection{Synthesis of ionic liquid-1(IL1)}

The ionic liquid required for preparing the lubricants were synthesized in the lab. All the solvents used were of analytical grade quality. A round bottom flask was filled with $10 \mathrm{mmol}$ of methylimidazole liquid $(0.82 \mathrm{gm})$ and $10 \mathrm{mmol}$ of [3MCPD] 3-Chloro-1, 2-propanediol (1.10 gm) in toluene as a reaction medium. The reacting agents were then kept at $80{ }^{\circ} \mathrm{C}$ for $48 \mathrm{hr}$ with constant stirring. When the reaction was completed, the ionic liquid formed was separated and washed with diethyl ether to get pure IL1. The formation of ionic liquid was confirmed by $1 \mathrm{H}-\mathrm{NMR}$ analysis.

The molecular weight of the developed liquid is 212.72 $\mathrm{gm} / \mathrm{mole}$. 1H-NMR analysis provided the results as; $1 \mathrm{H}$ NMR $(400 \mathrm{MHz}, \mathrm{CDCl} 3) \delta=8.9(\mathrm{~s}, 1 \mathrm{H}), 7.7(\mathrm{~d}, 2 \mathrm{H}), 5.9(\mathrm{~s}, 2 \mathrm{H}) 4.6$ $(\mathrm{d}, 2 \mathrm{H}), 3.6(\mathrm{~m} .4 \mathrm{H}), 3.5(\mathrm{~d}, 2 \mathrm{H}), 3.6(\mathrm{~s}, 3 \mathrm{H})$.

\subsection{Synthesis of ionic liquid-2(IL2)}

A $100 \mathrm{~mL}$ round bottom flask was filled with $10 \mathrm{mmol}$ of IL1 (1.92 gm) in water, in which $12 \mathrm{mmol}$ aqueous solution of NaBF4 (1.308 gm) was added. The reaction mixture was refluxed for about $12 \mathrm{hr}$.

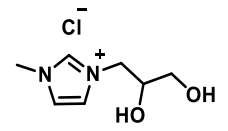

Chloride-based methyl-imidazolium ionic liquid (IL1)

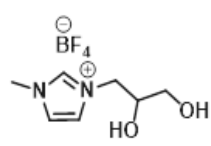

Tetrafluoroborate based methyl-imidazolium ionic liquid (IL2)

Figure 1. Molecular structure of ionic liquids

After the completion of the reaction, the water was evaporated by Rota-evaporator to get the IL2 ionic liquid. The $1 \mathrm{H}-\mathrm{NMR}$ analysis for IL2 is same as that of IL1. The molecular weight is $264.0651 \mathrm{gm} / \mathrm{mole}$.

\subsection{Friction and wear test}

The tribological tests were performed using a ball-on-flat configuration. The flat base sample was machined to the size of $30 \times 30 \times 10 \mathrm{~mm}$ from heat treated AISI 52100 bearing steel plates. Surface grinding was done to obtain a surface roughness of $0.2 \mu \mathrm{m}$. The $10 \mathrm{~mm}$ bearing ball was used as 
received. The chemical composition of AISI 52100 steel was ensured through spectroscopic analysis as per Table 1. The synthesized ionic liquids were blended with mineral base oil SAE 30 at various proportions viz. $0.5 \%, 1 \%$ and $1.5 \%$. The friction and wear tests were conducted using a reciprocating wear testing machine (TR-285-M9 Ducom, Bangalore). The details of the test setup are mentioned elsewhere [33]. A schematic of the contact is depicted in Figure 2. Table 2 presents the test parameters.

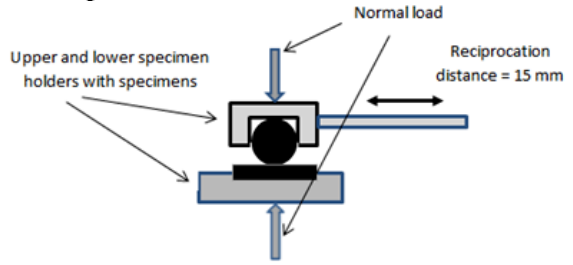

Figure 2. Schematic diagram of reciprocating contact
Table 1. The chemical composition of AISI 52100 steel

\begin{tabular}{|c|c|}
\hline Element & Chemical composition (Weight \%) \\
\hline Manganese & 0.57 \\
\hline Carbon & 0.96 \\
\hline Chromium & 1.09 \\
\hline Silicon & 0.21 \\
\hline Ferrous & 97.116 \\
\hline Sulfur & 0.023 \\
\hline
\end{tabular}

\subsection{Wear rate estimation}

Wear scar diameter on the $10 \mathrm{~mm}$ steel ball formed during the reciprocating wear tests were determined with the help of Dino-Lite Digital microscope for determining the wear rate. A representative image of the wear scar is shown in Figure 3, where two diameters are also marked.

Table 2. Test parameters

\begin{tabular}{|c|c|c|c|c|}
\hline Lubricant & Concentration of IL (\%) & Lubricant notation & Temperature $\left({ }^{\circ} \mathrm{C}\right)$ & Load (N) \\
\hline \multirow[b]{2}{*}{ Base oil } & \multirow{2}{*}{0} & \multirow{2}{*}{ B } & 50 & \multirow{13}{*}{20} \\
\hline & & & 100 & \\
\hline \multirow{6}{*}{ Base oil + IL1 } & \multirow{2}{*}{0.5} & \multirow{2}{*}{ L1 } & 50 & \\
\hline & & & 100 & \\
\hline & \multirow{2}{*}{1} & \multirow{2}{*}{ M1 } & 50 & \\
\hline & & & 100 & \\
\hline & \multirow[t]{2}{*}{1.5} & \multirow{2}{*}{ H1 } & 50 & \\
\hline & & & 100 & \\
\hline \multirow{6}{*}{ Base oil + IL2 } & \multirow{2}{*}{0.5} & \multirow{2}{*}{ L2 } & 50 & \\
\hline & & & 100 & \\
\hline & \multirow[b]{2}{*}{1} & \multirow{2}{*}{ M2 } & 50 & \\
\hline & & & 100 & \\
\hline & 1.5 & $\mathrm{H} 2$ & 50 & \\
\hline & & & 100 & \\
\hline
\end{tabular}

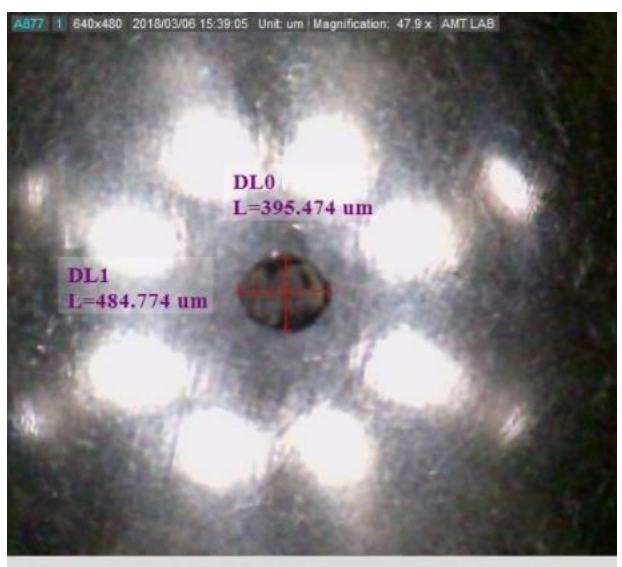

Figure 3. Wear scar image on steel ball used in $1.5 \% \mathrm{IL}+$ Base oil test at $50{ }^{\circ} \mathrm{C}$ 4.

The wear scar dimension was measured as shown in Figure

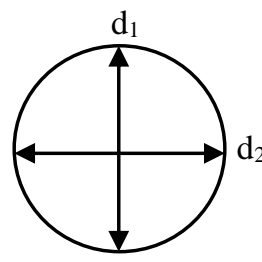

Figure 4. Wear scar diameter measurement of steel ball
Now, $d_{1}$ and $d_{2}$ are the diameters of the wear scar taken from the image of the steel.

$$
\mathrm{d}=\sqrt{d_{1} * d_{2}}
$$

where, $d=$ diameter of the wear scar

Wear volume is calculated from wear scar diameter (d) by considering the geometrical features [39]. So, the formula for wear volume $(\mathrm{V})$ is given as:

$$
\mathrm{v}=\frac{\pi \mathrm{h}}{6}\left(\frac{3 \mathrm{~d}^{2}}{4}+\mathrm{h}^{2}\right)
$$

where, $\mathrm{d}=$ diameter of wear scar; $\mathrm{h}=$ depth of wear scar

Also, the Wear scar depth (h) is given as:

$$
h=r-\sqrt{r^{2}-\frac{d^{2}}{4}}
$$

where, $r=$ Radius of steel ball $=5 \mathrm{~mm} ; \mathrm{d}=$ Diameter of the wear scar

The wear rate was calculated as follows:

$$
\mathrm{Q}=\frac{\mathrm{V}}{\mathrm{X}}
$$

where, $\mathrm{X}=$ Sliding distance $(\mathrm{m})$

Now, the sliding distance in $\mathrm{m}$ is calculated by the formula 
given below:

$$
X=0.002 \times t \times f \times L
$$

where, $\mathrm{t}=$ Test duration $=3600 \mathrm{~s}$

$$
\mathrm{f}=\text { Reciprocating frequency }=10 \mathrm{~Hz}
$$$$
\mathrm{L}=\text { Stroke length }=15 \mathrm{~mm}
$$

After completion of all the experiments, the surface characterization was done with the help of Atomic Force Microscopy (AFM) and Scanning Electron Microscopy (SEM). Also, the elemental composition of the reactive films formed on the surface is analyzed by Energy Dispersive X-ray Spectroscopy (EDS)

\section{RESULTS AND DISCUSSION}

\subsection{Analysis of coefficient of friction when tested with oil sample 1}

Tribological reciprocating wear tests were carried out with base oil at two different temperatures at $50{ }^{\circ} \mathrm{C}$ and $100^{\circ} \mathrm{C}$. The results of the base oil tests are not presented here. As shown in Figure 5, the lubricant L1 is more effective at higher temperatures. But, from Figure 6 and Figure 7, it is observed that the coefficient of friction is higher at $100{ }^{\circ} \mathrm{C}$ for the lubricants $\mathrm{M} 1$ and $\mathrm{H} 1$. It means the ionic liquid (IL) with $>1 \%$ IL1 shows better lubrication at lower temperatures. This happens because of the decomposition of oil sample 1 at $100{ }^{\circ} \mathrm{C}[40]$.

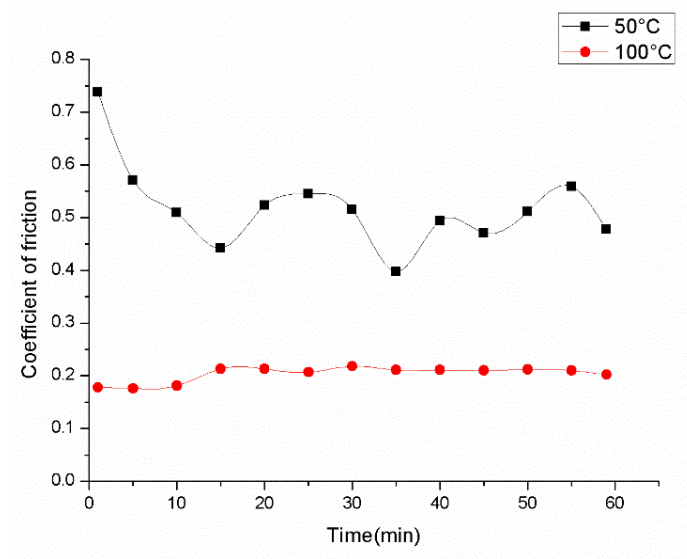

Figure 5. Variation of the coefficient of friction for the sample tested with lubricant L1

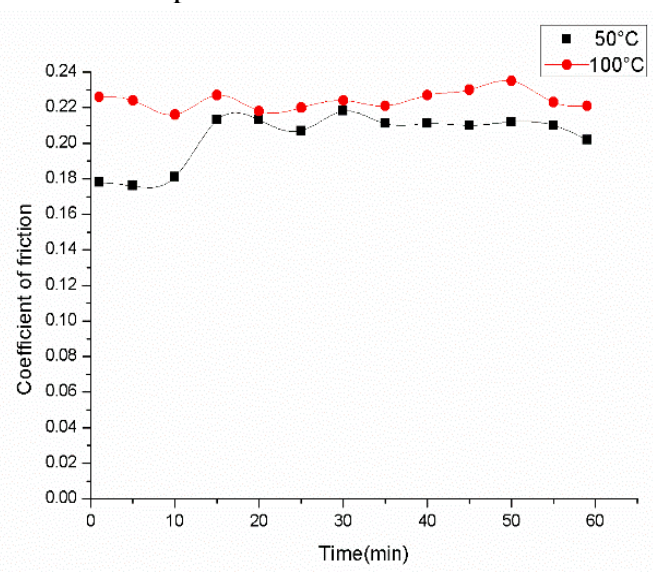

Figure 6. Variation of the coefficient of friction for the sample tested with lubricant M1

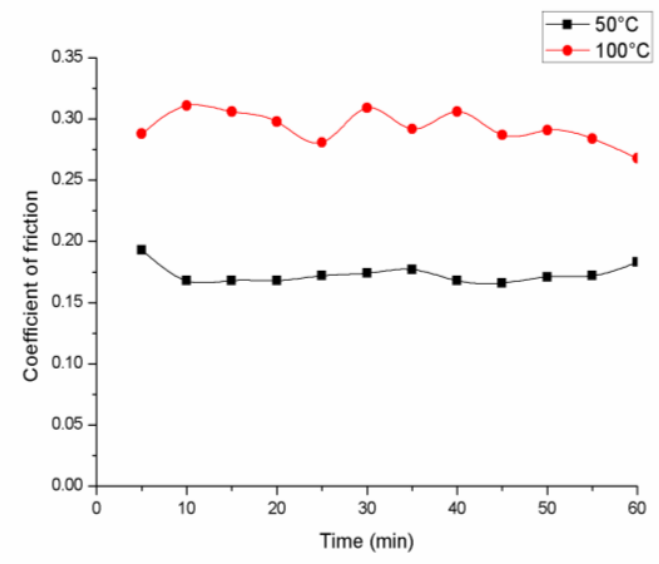

Figure 7. Variation of the coefficient of friction for the sample tested with lubricant $\mathrm{H} 1$

The comparison graphs presented in Figure 8 and Figure 9 show the variation of coefficient of friction at temperatures of $50{ }^{\circ} \mathrm{C}$ and $100{ }^{\circ} \mathrm{C}$. From Figure 10 , at $50{ }^{\circ} \mathrm{C}$, the coefficient of friction is the highest when tested with lubricant $\mathrm{B}$ when compared with the lubricants L1, M1, and H1. Also, the coefficient of friction decreases as the concentration of ionic liquid (IL) increases in the base oil. But, at $100{ }^{\circ} \mathrm{C}$, as shown in Figure 11, contrary to belief, the coefficient of friction is lowest for lubricant $\mathrm{B}$ when compared to ionic liquids.

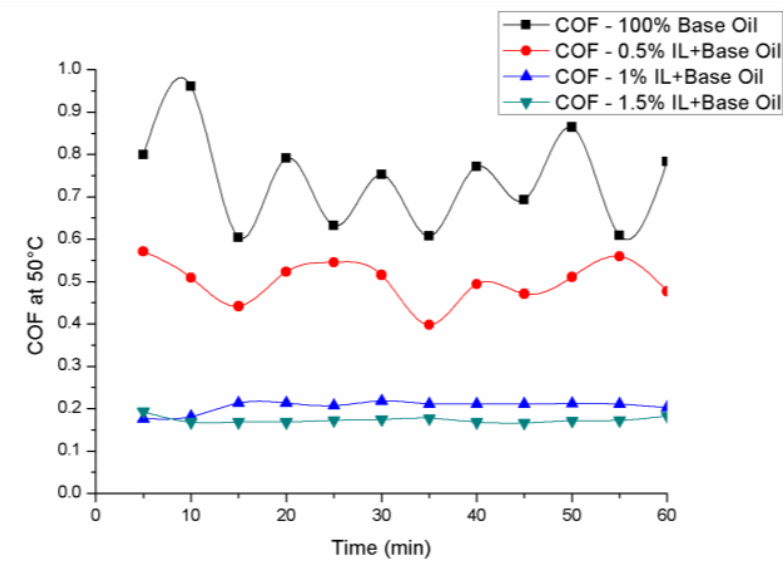

Figure 8. Comparison of the coefficient of friction for lubricants $\mathrm{B}, \mathrm{L} 1, \mathrm{M} 1$, and $\mathrm{H} 1$ at $50{ }^{\circ} \mathrm{C}$

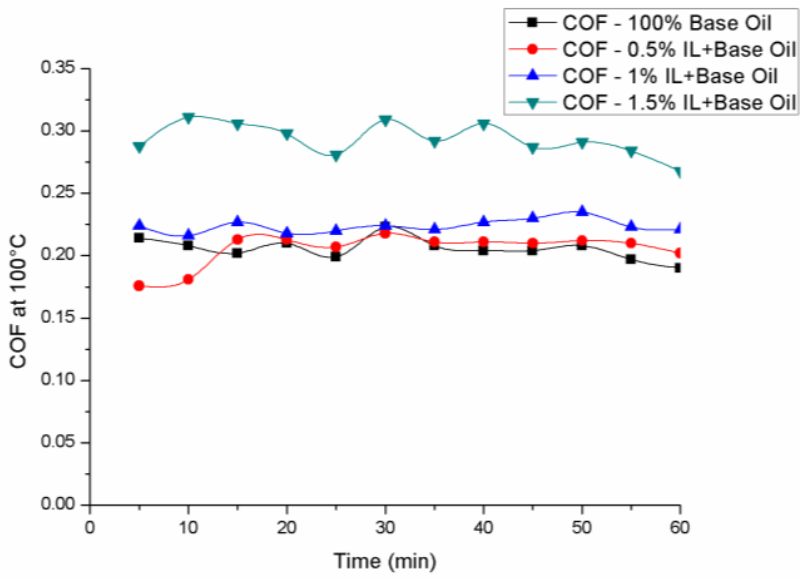

Figure 9. Comparison of the coefficient of friction for lubricants $\mathrm{B}, \mathrm{L} 1, \mathrm{M} 1$ and $\mathrm{H} 1$ at $100{ }^{\circ} \mathrm{C}$ 
When the concentration of ionic liquid increases in the base oil at $100{ }^{\circ} \mathrm{C}$, the coefficient of friction also increases which shows ionic liquid is more suitable at room temperature. As the concentration of IL increases in the base oil, the chlorine concentration increases, thereby increasing decomposition which breaks the surface reactive film in turn leading to an increase in coefficient of friction.

\subsection{Analysis of coefficient of friction when tested with oil sample 2}

In a similar way, the analysis of coefficient of friction using oil sample 2, methyl-imidazolium tetrafluoroborate (BF4- ion) was carried out after the test.

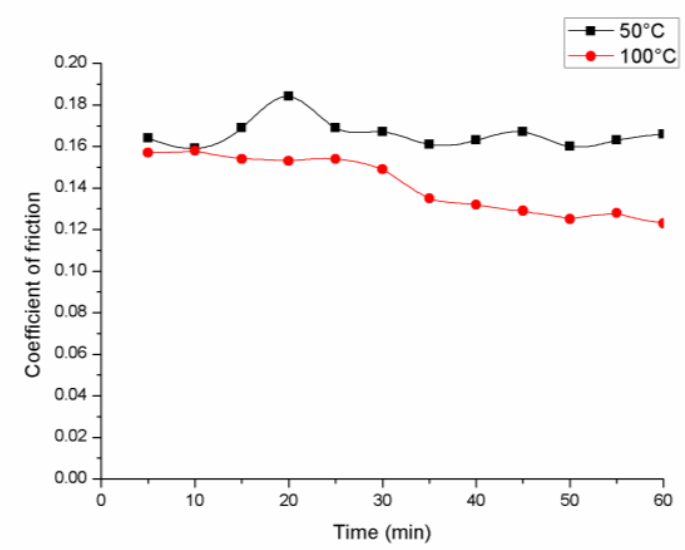

Figure 10. Variation of the coefficient of friction for the sample tested with lubricant L2

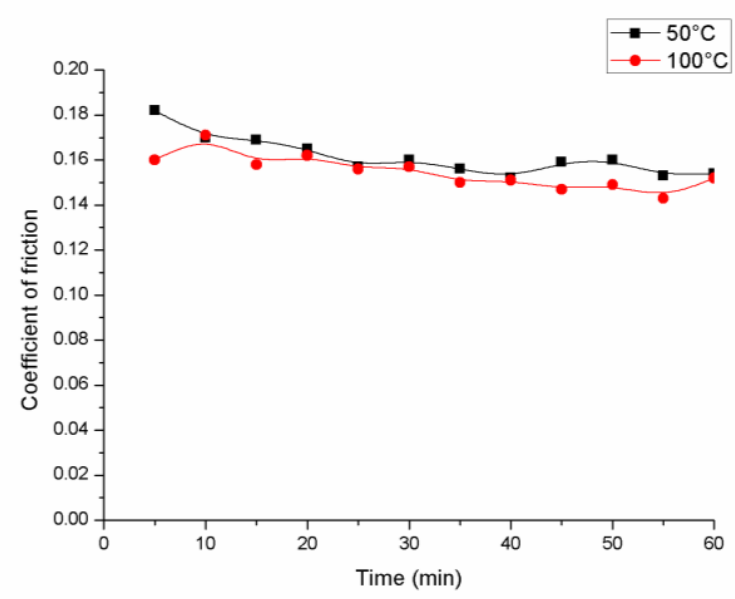

Figure 11. Variation of the coefficient of friction for the sample tested with lubricant M2

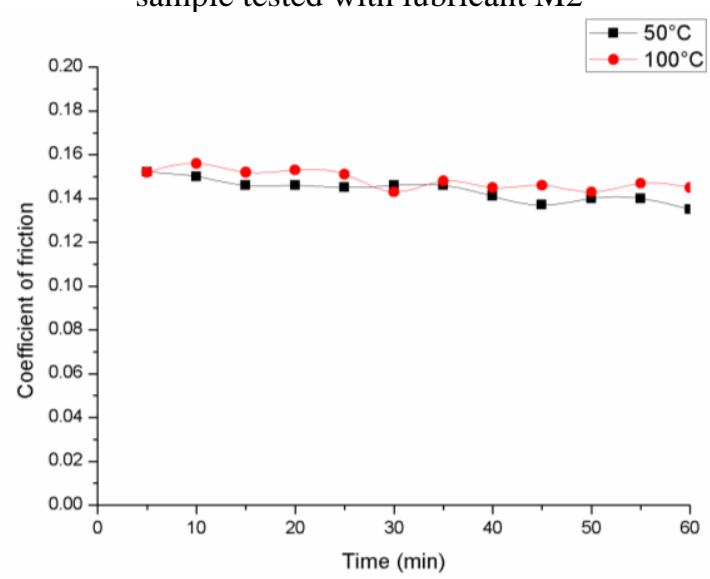

Figure 12. Variation of the coefficient of friction for the sample tested with lubricant $\mathrm{H} 2$
From the Figures 10, 11 and 12, we can state that the lubricants L2 and M2 show better friction reduction for $100{ }^{\circ} \mathrm{C}$ when compared to $50{ }^{\circ} \mathrm{C}$, whereas for lubricant $\mathrm{H} 2$, the coefficient of friction is almost similar for both temperatures. This shows the lubricant 2 (IL2+Base oil) performs better lubrication at higher temperatures. The comparison graphs are also plotted in order to understand the variation of friction coefficient at constant temperature (for $50{ }^{\circ} \mathrm{C}$ and $100{ }^{\circ} \mathrm{C}$ ) for various concentrations of IL2 in base oil and $100 \%$ base oil.

The plots clearly show that the friction coefficient between the steel ball and base sample decreases once the concentration of IL2 starts increasing in base oil at $50{ }^{\circ} \mathrm{C}$. Also, the addition of IL2 to the base oil decreases the friction coefficient from 0.8 to approximately 0.15 , which is $80 \%$ reduction in the friction at $50{ }^{\circ} \mathrm{C}$. At $100{ }^{\circ} \mathrm{C}$, however even though the addition of IL2 decreases the friction, there we can't see any definite trend between the concentration of IL2 and friction coefficient. Still, for $0.5 \%$ concentration of IL2 in base oil seems to be the best choice of lubrication at higher temperatures.

The graphs are plotted to understand the effectiveness of various oil samples at various concentrations and temperatures to reduce the friction between reciprocating sliding surfaces. Similar graphs are plotted for other temperatures and concentrations. From these, it can be confirmed that addition of ionic liquid to base oil decreases friction between surfaces for almost all cases. Also, it is clearly interpreted that lubricant 2 is more suitable for functional applications than lubricant 1at all concentrations and temperatures.

\subsection{Analysis of wear rate}

Figure 13 and 14 presents the wear rate values for all the tribological tests carried out with lubricants 1 and 2 at $50{ }^{\circ} \mathrm{C}$ and $100{ }^{\circ} \mathrm{C}$ respectively. At $50{ }^{\circ} \mathrm{C}$, the wear rate of all concentrations is less than base oil and $\mathrm{B} 1$ at $50{ }^{\circ} \mathrm{C}$ showed the lowest wear rate. At $100^{\circ} \mathrm{C}$, some deviations were seen in the graph that $\mathrm{M} 1$ at $100{ }^{\circ} \mathrm{C}$ showed almost same wear rate as that of base oil whereas the $\mathrm{L} 1$ at $100{ }^{\circ} \mathrm{C}$ has the lowest wear rate. The wear rate of $\mathrm{IL}+$ base oil at $50{ }^{\circ} \mathrm{C}$ is less as compared to when at $100{ }^{\circ} \mathrm{C}$. So, the lubricant $\mathrm{L} 1$ showed the best results compared to other concentrations of ionic liquids and base oil.

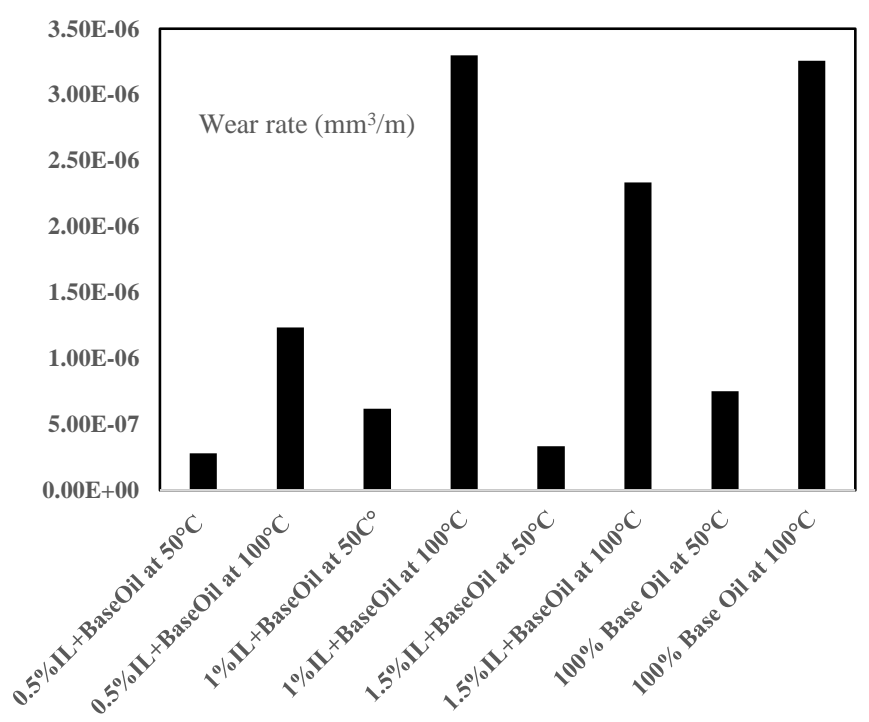

Figure 13. Wear rate of samples tested with lubricants B, L1, $\mathrm{M} 1$ and $\mathrm{H} 1$ at temperatures of $50{ }^{\circ} \mathrm{C}$ and $100{ }^{\circ} \mathrm{C}$ 


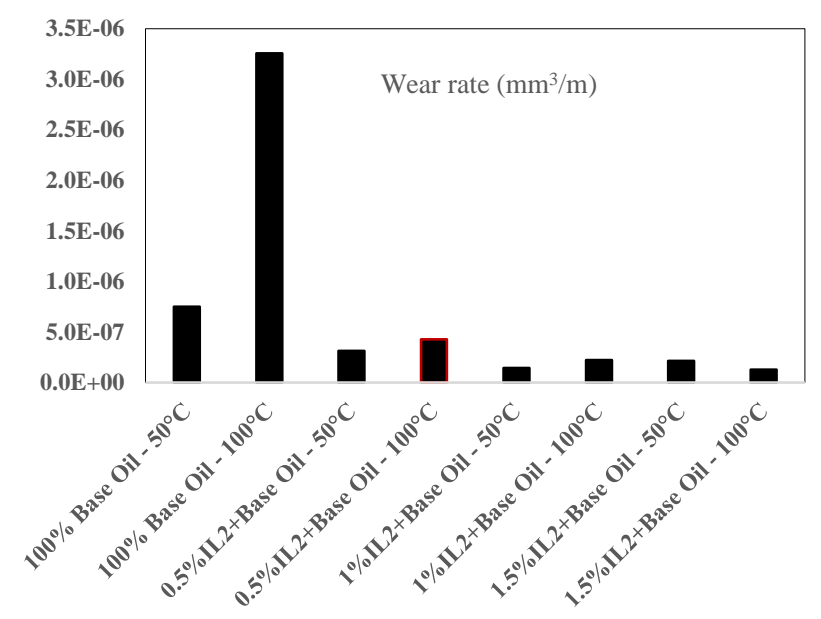

Figure 14. Wear rate of samples tested with lubricants B, L2, $\mathrm{M} 2$ and $\mathrm{H} 2$ at temperatures of $50{ }^{\circ} \mathrm{C}$ and $100{ }^{\circ} \mathrm{C}$

\subsection{Surface analysis}

The Atomic Force Microscopy (AFM) of the samples tested with IL+ base oil was done in order to analyze the wear track observed on the sample. The AFM was done for $1 \%$ IL+ base oil at $50{ }^{\circ} \mathrm{C}$ and for all concentrations of IL+ base oil at $100{ }^{\circ} \mathrm{C}$. The remaining two concentrations at $50{ }^{\circ} \mathrm{C}$ were left out because the surface of the lower flat samples was found to be corroded. For the sample tested with $1 \%$ IL+base Oil at $50^{\circ} \mathrm{C}$, Figure 15 shows smooth surfaces in AFM with no evidence of peaks whatsoever. This smooth surface with roughness 303 $\mathrm{nm}$ indicates the presence of reactive films which confirms further friction reduction. Also, from Figure 16, AFM image of the sample with $0.5 \%$ IL+base Oil at $100{ }^{\circ} \mathrm{C}$ has very small peaks but the surface seems unaffected by wear. No presence of the reactive films on the surface is confirmed. As shown in Figure 17 , the sample with $1 \%$ IL+Base oil tested at $100{ }^{\circ} \mathrm{C}$ clearly shows the presence of deep grooves. The absence of white patches further confirms high friction and wear. In Figure 18, the AFM image of the sample with $1.5 \%$ IL+Base oil at $100{ }^{\circ} \mathrm{C}$ shows intermediate discontinuous tribo-film formation. Traces of reactive films are observed on the surface indicating that minor corrosive wear has occurred. Also, it shows intermediate deep grooves thereby increasing the surface roughness to about $884 \mathrm{~nm}$.
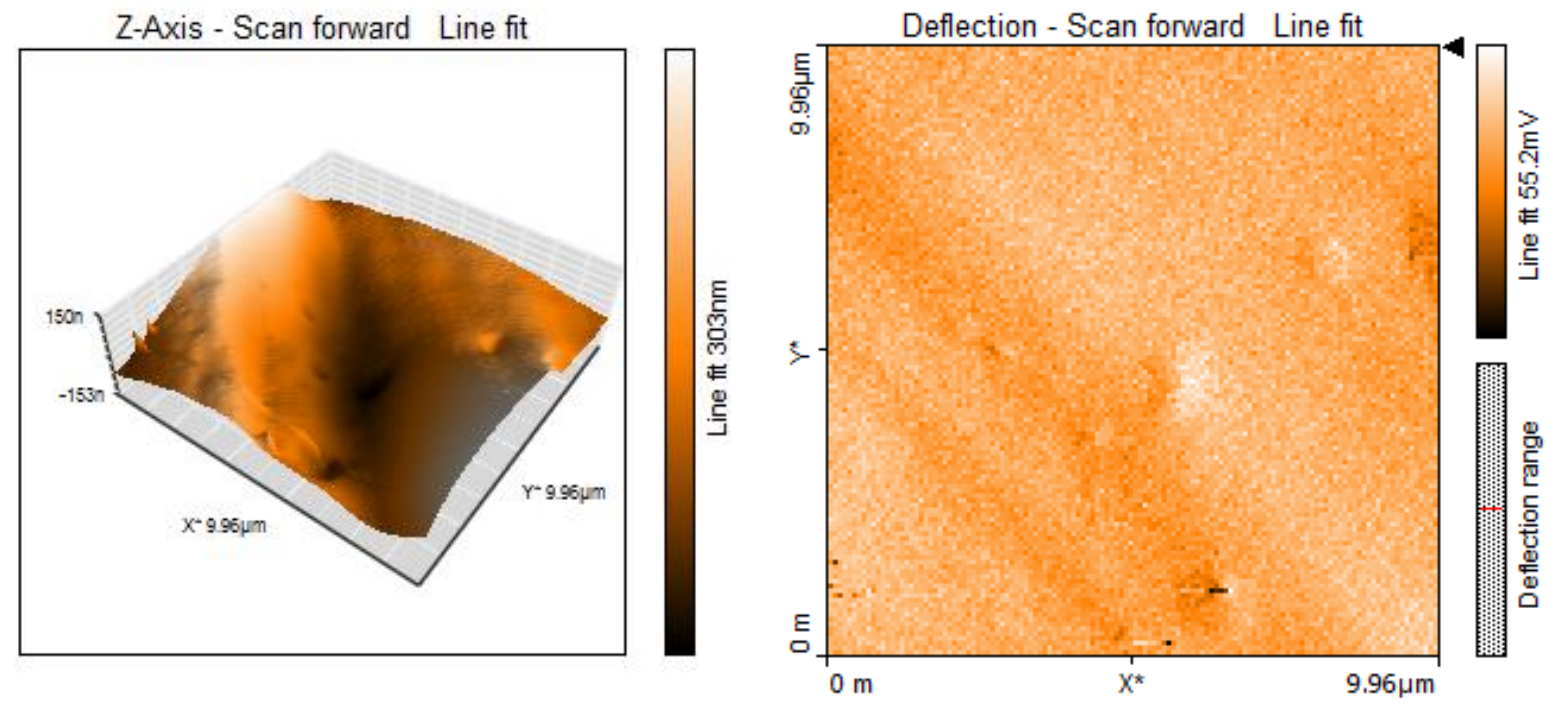

Figure 15. AFM image obtained of wear track of sample tested with lubricant M1 at $50{ }^{\circ} \mathrm{C}$
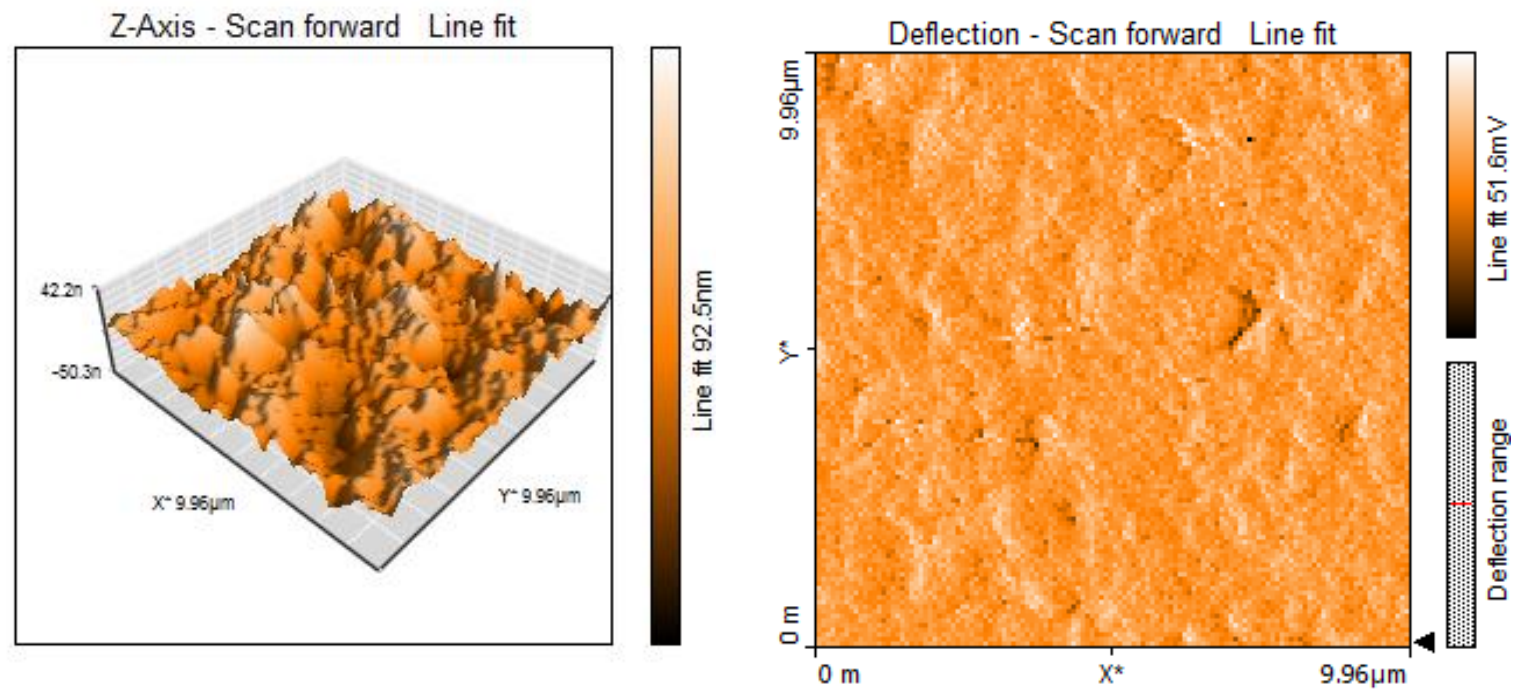

Figure 16. AFM image obtained of wear track of sample tested with lubricant L1 at $100{ }^{\circ} \mathrm{C}$ 

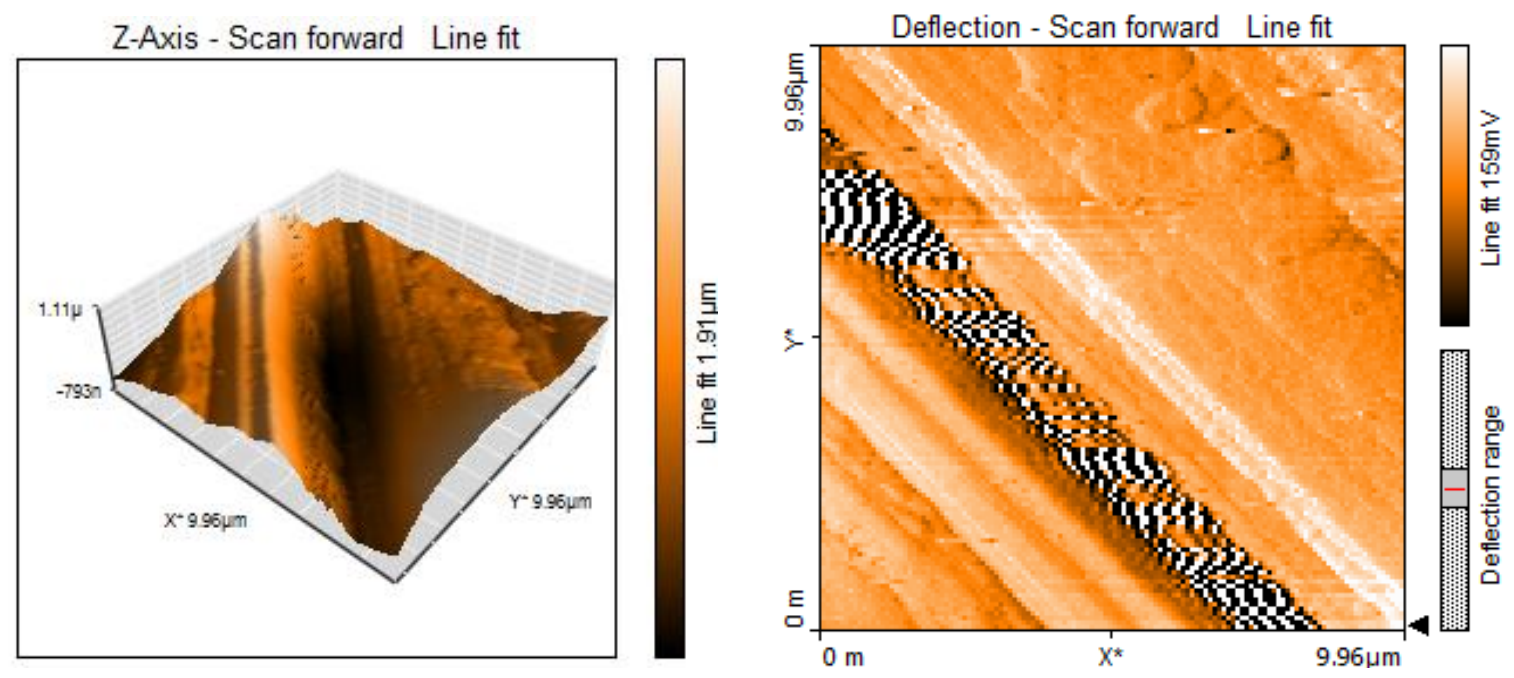

Figure 17. AFM image obtained of wear track of sample tested with $\mathrm{M} 1$ at $100{ }^{\circ} \mathrm{C}$
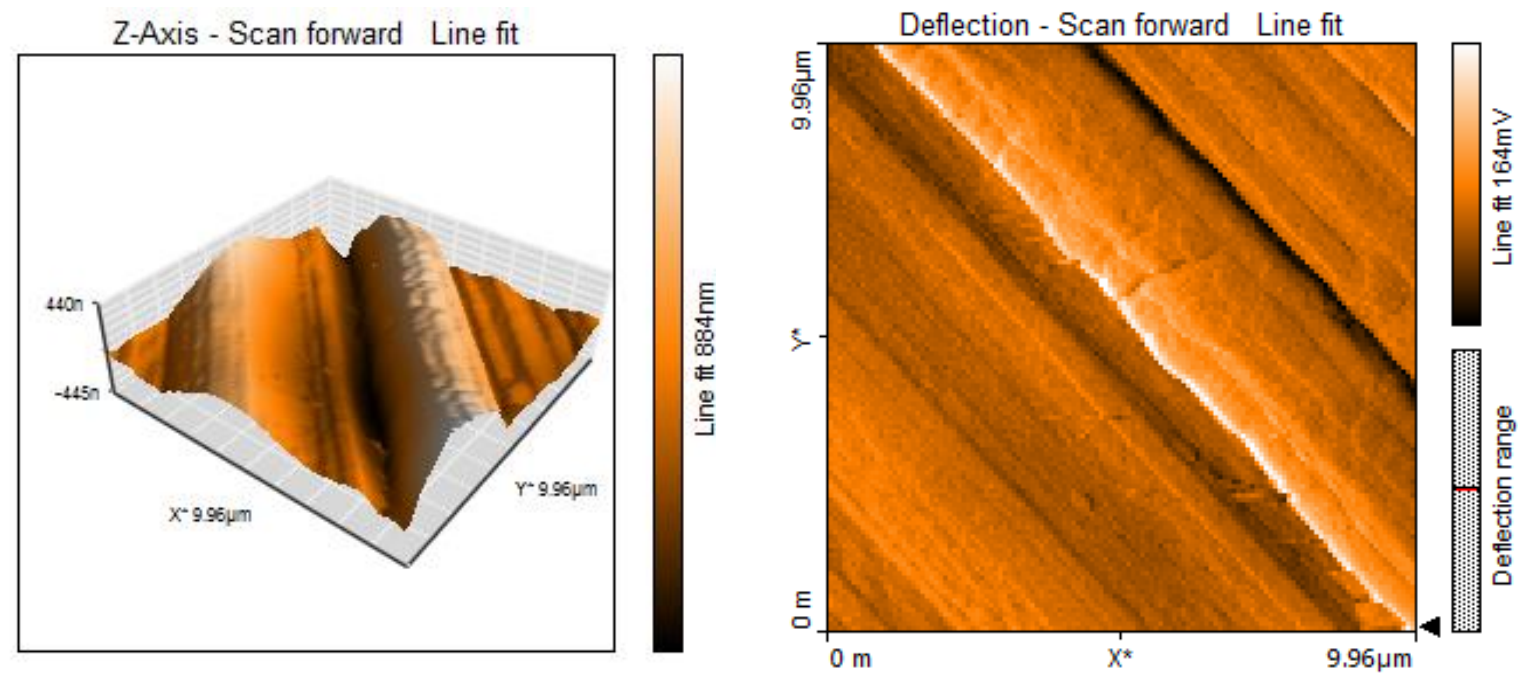

Figure 18. AFM image obtained of wear track of sample tested with $\mathrm{H} 1$ at $100{ }^{\circ} \mathrm{C}$

Figures 19-23 presents the results of the SEM/EDS analysis carried out on the surface of the samples. All the images were taken at a magnification of $2000 \mathrm{X}$. Figure 19 (a) presents the SEM image of the flat sample tested at $100{ }^{\circ} \mathrm{C}$ with lubricant B. Wear particles are seen along the sliding direction. As there are no additives added in lubricant B, wear will be high compared to the other lubricants. When tested at $50{ }^{\circ} \mathrm{C}$, worn particles were not seen, but only the sliding marks were seen which proves that the surface was not severely affected.

In Figure 20 (a), for the sample tested with $1 \%$ IL1+Base oil at $100{ }^{\circ} \mathrm{C}$, black marks are observed which show that some surface reactions have occurred. Also, from EDS in Figure 20 (a), it is seen that 0.02 weight $\%$ of chlorine was present from the ionic liquid and the remaining Ferrous and carbon contents were from the base metal AISI 52100 steel sample used. When tested with $\mathrm{H} 1$ lubricant at $50{ }^{\circ} \mathrm{C}$, fine parallel wear marks which are surrounded by deep parallel wear marks were observed. A significant amount of chlorine (around 0.04 weight \%) was from the IL1.

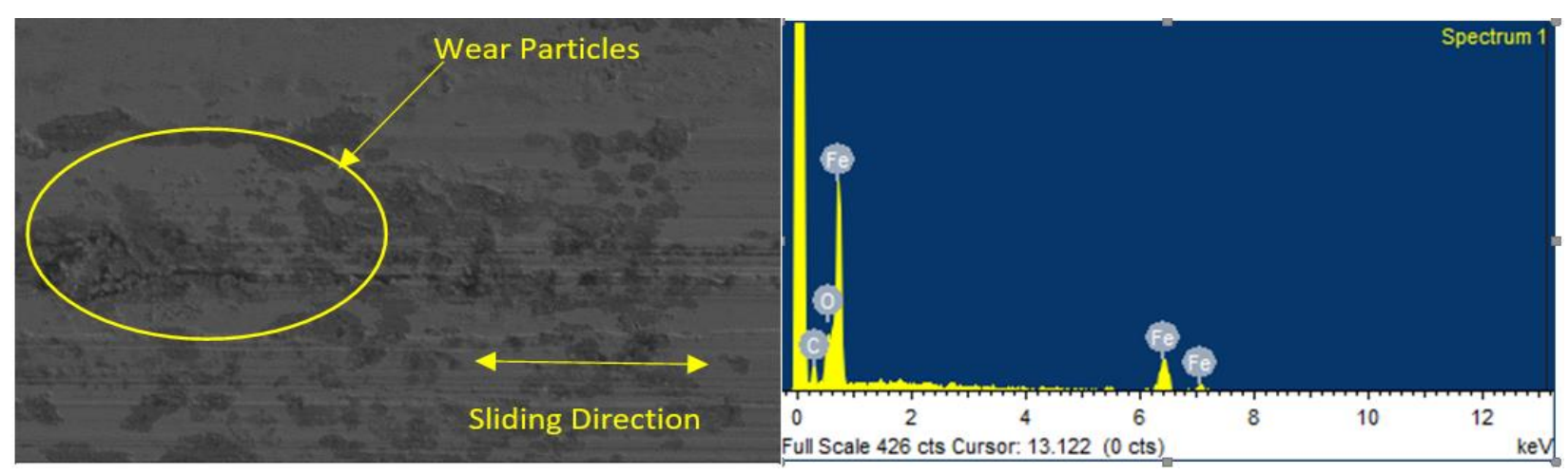

Figure 19. (a) SEM image and (b) EDS image of wear track of flat sample tested with lubricant $\mathrm{B}$ at $100{ }^{\circ} \mathrm{C}$ 


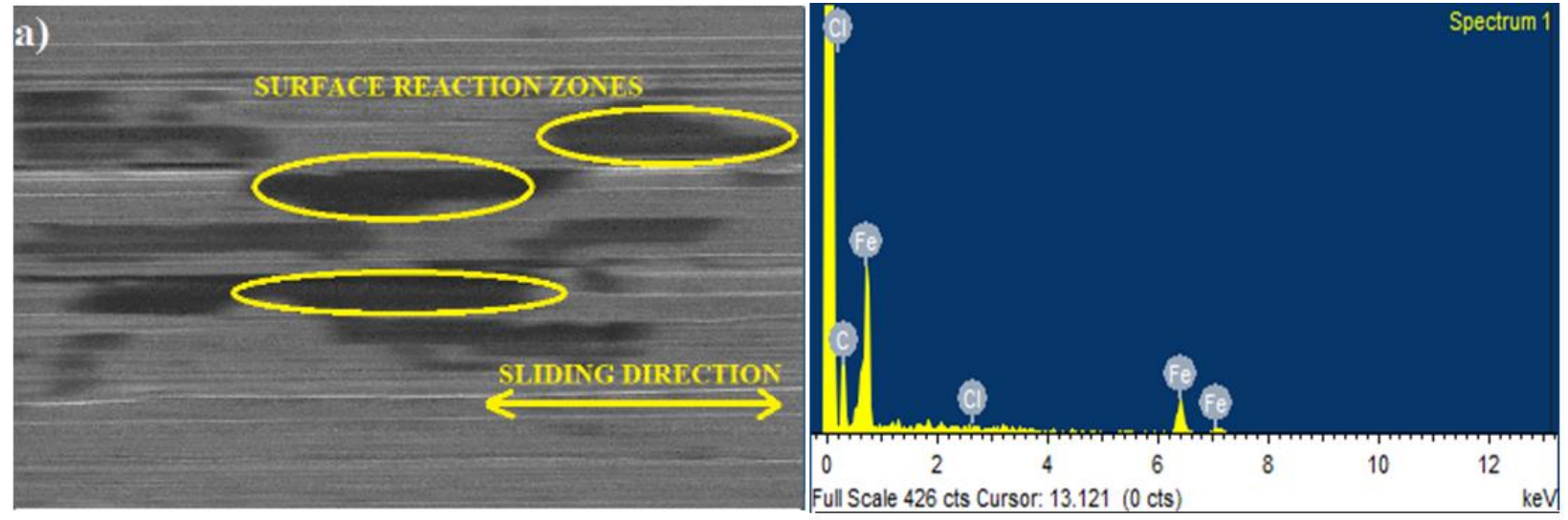

Figure 20. (a) SEM image and (b) EDS spectrum of wear track of flat sample tested with lubricant $\mathrm{M} 1$ at $100{ }^{\circ} \mathrm{C}$

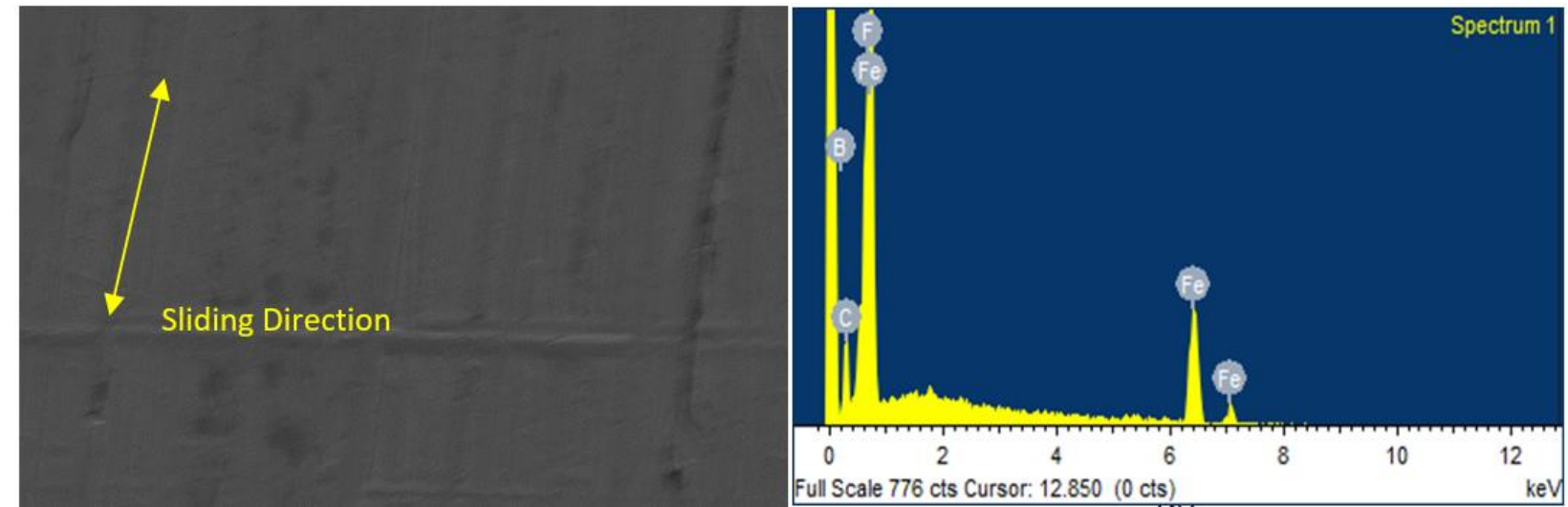

Figure 21. (a) SEM image (b) EDS spectrum of wear track of flat sample tested with lubricant M2 at $100{ }^{\circ} \mathrm{C}$

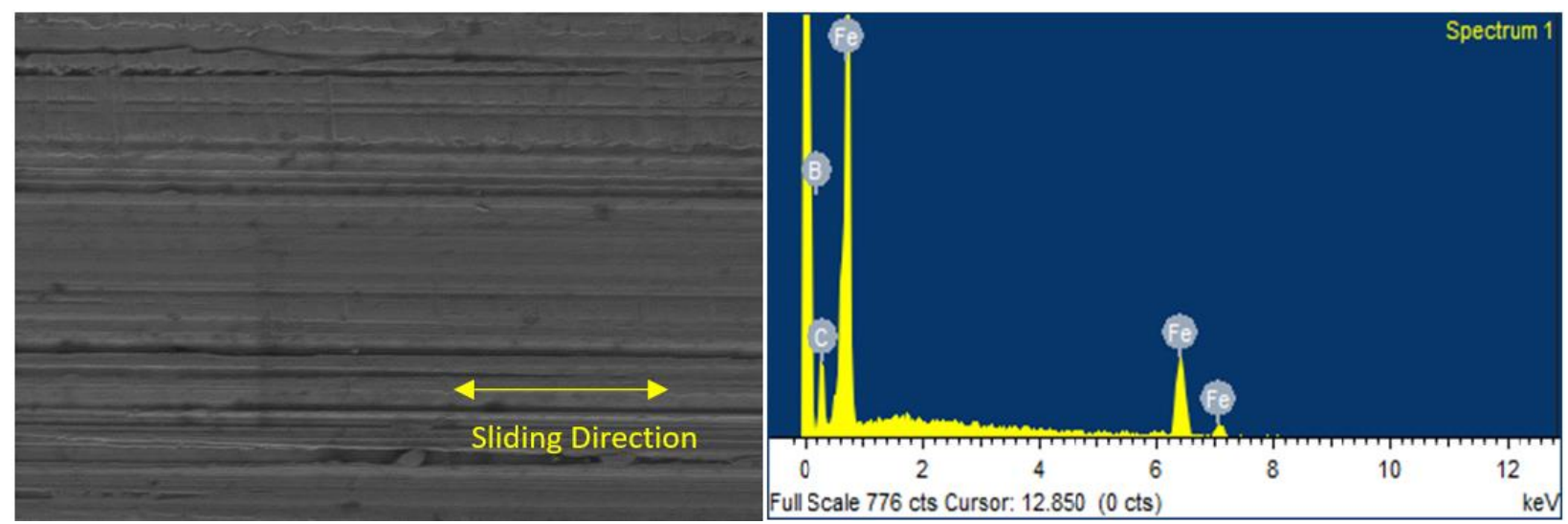

Figure 22. (a) SEM image (b) EDS spectrum of wear track of flat sample tested with lubricant $\mathrm{H} 2$ at $50{ }^{\circ} \mathrm{C}$

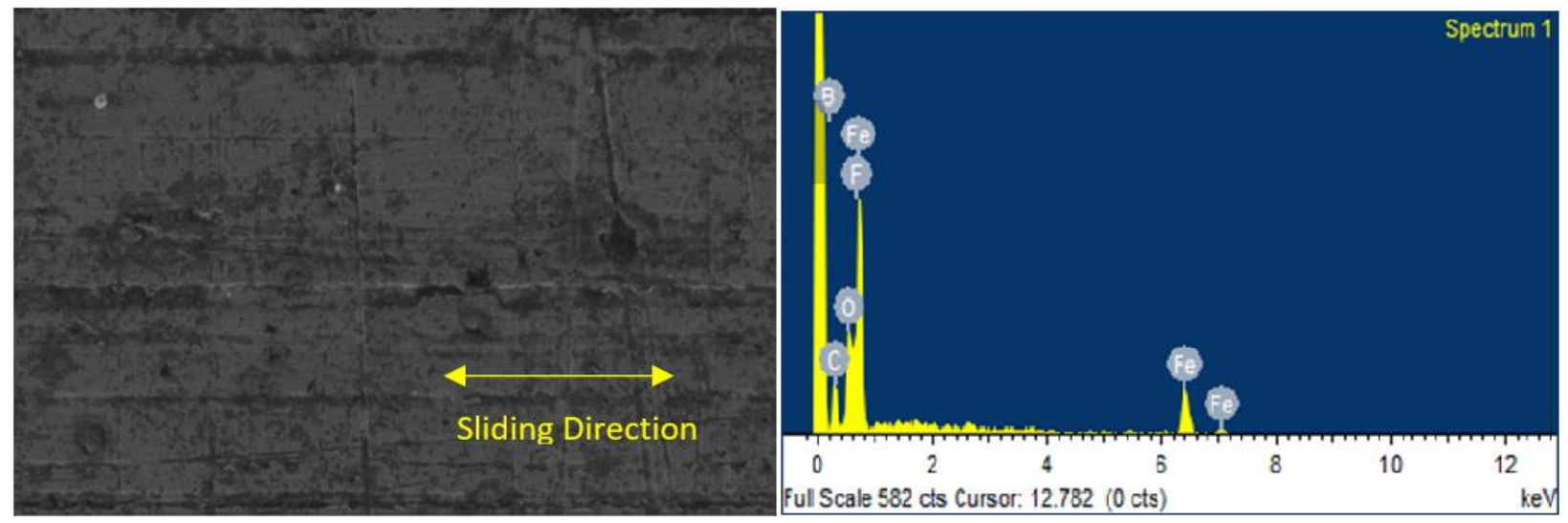

Figure 23. (a) SEM image (b) EDS spectrum of wear track of flat sample tested with lubricant $\mathrm{H} 2$ at $100{ }^{\circ} \mathrm{C}$ 
Table 3 presents the elemental results of the EDS analysis.

Table 3. Results of the elemental analysis

\begin{tabular}{|c|c|c|c|}
\hline Specimen & Element & Weight \% & Atomic\% \\
\hline \multirow{3}{*}{$\begin{array}{l}\text { B tested } \\
\text { at } \\
100{ }^{\circ} \mathrm{C}\end{array}$} & $\mathrm{C}$ & 6.23 & 21.11 \\
\hline & $\mathrm{O}$ & 5.85 & 14.87 \\
\hline & $\mathrm{Fe}$ & 87.92 & 64.03 \\
\hline \multirow{3}{*}{$\begin{array}{c}\text { M1 tested } \\
\text { at } \\
100{ }^{\circ} \mathrm{C}\end{array}$} & $\mathrm{C}$ & 23.23 & 58.45 \\
\hline & $\mathrm{Cl}$ & 0.02 & 0.02 \\
\hline & $\mathrm{Fe}$ & 76.75 & 41.53 \\
\hline \multirow{4}{*}{$\begin{array}{c}\text { M2 tested } \\
\text { at } \\
100^{\circ} \mathrm{C}\end{array}$} & B & 3.67 & 13.56 \\
\hline & $\mathrm{C}$ & 6.26 & 20.83 \\
\hline & $\mathrm{F}$ & 0.85 & 1.79 \\
\hline & $\mathrm{Fe}$ & 89.22 & 63.82 \\
\hline \multirow{3}{*}{$\begin{array}{c}\mathrm{H} 2 \text { tested } \\
\text { at } \\
50^{\circ} \mathrm{C} \\
\end{array}$} & $\mathrm{B}$ & 2.64 & 9.58 \\
\hline & C & 8.63 & 28.15 \\
\hline & $\mathrm{Fe}$ & 88.73 & 62.27 \\
\hline \multirow{5}{*}{$\begin{array}{c}\mathrm{H} 2 \text { tested } \\
\text { at } \\
100^{\circ} \mathrm{C}\end{array}$} & $\mathrm{B}$ & 24.29 & 47.60 \\
\hline & C & 12.61 & 22.24 \\
\hline & $\mathrm{O}$ & 6.51 & 8.62 \\
\hline & $\mathrm{F}$ & 0.11 & 0.13 \\
\hline & $\mathrm{Fe}$ & 56.47 & 21.42 \\
\hline
\end{tabular}

When tested with $1 \%$ IL2+Base oil at $50^{\circ} \mathrm{C}$, fine wear marks were observed. EDS analysis showed, 3.71 weight $\%$ of boron in the specimen. In Figure 21, wear marks were not seen clearly, but the EDS results showed that 3.67 weight \% of boron and 0.85 weight $\%$ of fluorine present in the sample. In the sample tested with $1.5 \%$ IL2+Base oil as presented in Figure 22, wear tracks were clearly seen and boron of 2.64 weight $\%$ was found. From Figure 23, it may be seen that the surface has been damaged due to wear and 24.29 weight $\%$ of boron was found which is the highest of all the IL2 samples indicating that higher concentration of boron present on the surface.

\section{CONCLUSIONS}

- Two different ionic liquids IL1 (chloride based methyl-imidazolium ionic liquid) and IL2 (tetrafluoroborate based methyl-imidazolium ionic liquid) were mixed with base oil at three weight percentages $0.5 \%, 1 \%$ and $1.5 \%$, were then tested in reciprocating wear testing machine at two temperatures of $50{ }^{\circ} \mathrm{C}$ and $100{ }^{\circ} \mathrm{C}$.

- Overall, it can be observed that the results of IL2+Base Oil were found to be better than IL1+Base Oil. This proves that the tetrafluoroborate ion is more reactive than chloride ion to reduce the friction between the sliding surfaces by forming tribological reaction films. The coefficient of friction was found to be low for IL2+Base Oil for all concentrations and temperatures. The addition of chloridebased methyl-imidazolium ionic liquid (IL1) to base oil has decreased the friction at $50^{\circ} \mathrm{C}$. At higher temperature of $100^{\circ} \mathrm{C}$, it has been observed that the addition of IL1 to base oil has instead increased the coefficient of friction. This proves that the IL1 is more suitable for lubrication applications at lower temperatures. Whereas for IL2 is added to base oil the coefficient of friction has decreased at both $50^{\circ} \mathrm{C}$ and $100^{\circ} \mathrm{C}$.

- The wear rate is determined for all the wear tested sample in addition to the friction testing. Wear rate for all oil samples including base oil, oil sample 1 and oil sample 2 at low temperatures was less as compared to high temperatures. The wear rate for samples tested with IL1+Base Oil was found to increase as the temperature was increased. Whereas, the samples tested with IL2+Base Oil showed results better than IL1 at both high and low temperatures.

- $\quad$ AFM, SEM and EDAX analysis are used for surface characterization of all the tribologically wear tested samples. The AFM shows the formation chemically reacted of tribofilms on the surface which proves the reduction of friction and wear. The SEM images are used to analyze the wear tracks of the samples at microscopic level showing worn particles and wear marks. EDAX analysis indicates the deposition of chlorine, boron and fluorine on the wear tracks of the respective samples.

\section{REFERENCES}

[1] Minami, I. (2009). Ionic liquids in tribology. Molecules, 14(6): 2286-2305. https://doi.org/10.3390/molecules14062286

[2] Smith, P.G. (1961). High-temperature molten-salt lubricated hydrodynamic journal bearings. ASLE Transactions, 4(2): 263-274. https://doi.org/10.1007/978-0-387-92897-5_955

[3] Welton, T. (1999). Room-temperature ionic liquids. Solvents for synthesis and catalysis. Chemical Reviews, 99(8): 2071-2084. https://doi.org/10.1021/cr980032t

[4] Earle, M.J., Seddon, K.R. (2000). Ionic liquids. Green solvents for the future. Pure and Applied Chemistry, 72(7): http://dx.doi.org/10.1351/pac20007207139 1391-1398.

[5] Ye, C.F., Liu, W.M., Chen, Y.X., Yu, L.G. (2001). Room-temperature ionic liquids: A novel versatile lubricant. Chemical Communications, 21: 2244-2245. https://doi.org/10.1039/B106935G

[6] Reich, R.A., Stewart, P.A., Bohaychick, J., Urbanski, J.A. (2003). Base oil properties of ionic liquids (C). Tribology \& Lubrication Technology, 59(7), 16. https://doi.org/10.3390/lubricants5030031

[7] Wang, H.Z., Lu, Q.M., Ye, C.F., Liu, W.M., Cui, Z.J. (2004). Friction and wear behaviors of ionic liquid of alkyl imidazolium hexafluorophosphates as lubricants for steel/steel contact. Wear, 256(1-2): 44-48. https://doi.org/10.1016/S0043-1648(03)00255-2

[8] Sanes, J., Carrión, F.J., Jiménez, A.E., Bermúdez, M.D. (2007). Influence of temperature on PA 6-steel contacts in the presence of an ionic liquid lubricant. Wear, 263(16): 658-662. https://doi.org/10.1016/j.wear.2006.11.034

[9] Espinosa, T., Jiménez, A.E., Martínez-Nicolás, G., Sanes, J., Bermúdez, M.D. (2014). Abrasion resistance of magnesium alloys with surface films generated from phosphonate imidazolium ionic liquids. Applied Surface Science, (320): https://doi..org/10.1016/j.apsusc.2014.09.077

[10] Pu, J., Huang, D., Wang, L., Xue, Q. (2010). Tribology study of dual-layer ultrathin ionic liquid films with bonded phase: Influences of the self-assembled underlayer. Colloids and Surfaces A: Physicochemical and Engineering Aspects, 372(1-3): 155-164. https://doi.org/10.1016/j.colsurfa.2010.10.017

[11] Fan, M., Wang, X., Yang, D., Wang, D., Yan, Y., Zhang, C., Liu, X. (2015). New ionic liquid lubricants derived from nonnutritive sweeteners. Tribology International, 92:

344-352. 
[12] Han, Y.Y., Qiao, D., Zhang, L., Feng, D.P. (2015). Study of tribological performance and mechanism of phosphonate ionic liquids for steel/aluminum contact. Tribology International, 84: 71-80. https://doi.org/10.1016/j.triboint.2014.11.013

[13] Jiménez, A.E., Bermudez, M.D., Iglesias, P., Carrión, F.J., Martínez-Nicolás, G. (2006). 1-N-alkyl-3methylimidazolium ionic liquids as neat lubricants and lubricant additives in steel- aluminum contacts. Wear, 260(7-8):

766-782. https://doi.org/10.1016/j.wear.2005.04.016

[14] Jimenez, A.E., Bermudez, M.D., Carrion, F.J., MartinezNicolas, G. (2006). Room temperature ionic liquids as lubricant additives in steel- aluminum contacts: Influence of sliding velocity, normal load, and temperature. Wear, 261(3-4):

$347-359$ https://doi.org/10.1016/j.wear.2005.11.004

[15] Sanes, J., Carrion, F.J., Bermudez, M.D., MartinezNicolas, G. (2006). Ionic liquids as lubricants of polystyrene and polyamide 6-steel contacts. Preparation and properties of new polymer-ionic liquid dispersions. Tribology Letters, $21(2)$ : 121. https://doi.org/10.1007/s11249-006-9028-5

[16] Uerdingen, M., Treber, C., Balser, M., Schmitt, G., Werner, C. (2005). Corrosion behavior of ionic liquids. Green Chemistry, 7(5): 321-325. https://doi.org/10.1039/B419320M

[17] Perissi, I., Bardi, U., Caporali, S., Lavacchi, A. (2006). High temperature corrosion properties of ionic liquids. Corrosion Science, 48(9): 2349-2362. https://doi.org/10.1016/j.corsci.2006.06.010

[18] Phillips, B.S., John, G., Zabinski, J.S. (2007). Surface chemistry of fluorine containing ionic liquids on steel substrates at elevated temperature using Mössbauer spectroscopy. Tribology Letters, 26(2): 85-91. https://doi.org/10.1007/s11249-006-9020-0

[19] Pisarova, L., Gabler, C., Dörr, N., Pittenauer, E., Allmaier, G. (2012). Thermo-oxidative stability and corrosion properties of ammonium based ionic liquids. $\begin{array}{llll}\text { Tribology } & \text { International, } & \text { 46(1): }\end{array}$ https://doi.org/10.1016/j.triboint.2011.03.014

[20] Gusain, R., Singh, R., Sivakumar, K.L.N., Khatri, O.P. (2014). Halogen-free imidazolium/ammonium-bis (salicylato) borate ionic liquids as high performance lubricant additives. RSC Advances, 4(3): 1293-1301. https://doi.org/10.1039/C3RA43052A

[21] Mahrova, M., Pagano, F., Pejakovic, V., Valea, A., Kalin, M., Igartua, A., Tojo, E. (2015). Pyridinium based dicationic ionic liquids as base lubricants or lubricant additives. Tribology International, 82: 245-254. https://doi.org/10.1016/j.triboint.2014.10.018

[22] Yu, B., Bansal, D.G., Qu, J., Sun, X.Q., Luo, H.M., Dai, S., Blau, P.J., Bunting, B.G., Mordukhovich, G., Smolenski, D.J. (2012). Oil-miscible and non-corrosive phosphonium-based ionic liquids as candidate lubricant additives. Wear, 289: 58-64 https://doi.org/10.1016/j.wear.2012.04.015

[23] Cai, Z.B., Meyer III, H.M., Ma, C., Chi, M.F., Luo, H.M., $\mathrm{Qu}$, J. (2014). Comparison of the tribological behavior of steel-steel and $\mathrm{Si}_{3} \mathrm{~N}_{4}$-steel contacts in lubricants with ZDDP or ionic liquid. Wear, 319(1-2): 172-183. https://doi.org/10.1016/j.wear.2014.08.002

[24] Qu, J., Luo, H.M., Chi, M.F., Ma, C., Blau, P.J., Dai, S., Viola, M.B. (2014). Comparison of an oil-miscible ionic liquid and ZDDP as a lubricant anti-wear additive. Tribology International, 71: 88-97. https://doi.org/10.1016/j.triboint.2013.11.010

[25] Qu, J., Meyer, H.M., Cai, Z.B., Ma, C., Luo, H. (2015). Characterization of ZDDP and ionic liquid tribofilms on non-metallic coatings providing insights of tribofilm formation mechanisms. Wear, 332-333: 1273-1285, https://doi.org/10.1016/j.wear.2015.01.076

[26] Anand, M., Hadfield, M., Viesca, J.L., Thomas, B., Battez, A.H., Austen, S. (2015). Ionic liquids as tribological performance improving additive for inservice and used fully-formulated diesel engine lubricants. Wear, 334-335: 67-74. https://doi.org/10.1016/j.wear.2015.01.055

[27] González, R., Bartolomé, M., Blanco, D., Viesca, J.L., Fernández-González, A., Battez, A.H. (2016). Effectiveness of phosphonium cation-based ionic liquids as lubricant additive. Tribology International, 98: 82-93. https://doi.org/10.1016/j.triboint.2016.02.016

[28] Battez, A.H., Bartolomé, M., Blanco, D., Viesca, J.L., Fernández-González, A., González, R. (2016). Phosphonium cation-based ionic liquids as neat lubricants: Physicochemical and tribological performance. Tribology International, 95: 118-131. https://doi.org/10.1016/j.triboint.2015.11.015

[29] Zhu, L., Zhao, G., Wang, X. (2017). Investigation on three oil-miscible ionic liquids as antiwear additives for polyol esters at elevated temperature. Tribology International, 109: 336-345. https://doi.org/10.1016/j.triboint.2016.10.032

[30] Välbe, R., Tarkanovskaja, M., Mäeorg, U., Reedo, V., Lohmus, A., Taaber, T., Lõhmus, R. (2017). Phosphonium-based ionic liquids mixed with stabilized oxide nanoparticles as highly promising lubricating oil additives. Proceedings of the Estonian Academy of Sciences, 66(2): 174. https://doi.org/10.3176/proc.2017.2.05

[31] Reeves, C.J., Siddaiah, A., Menezes, P.L. (2018). Tribological study of imidazolium and phosphonium ionic liquid-based lubricants as additives in carboxylic acid-based natural oil: Advancements in environmentally friendly lubricants. Journal of Cleaner Production, 176: 241-250. https://doi.org/10.1016/j.jclepro.2017.12.099

[32] Monge, R., González, R., Battez, A.H., FernándezGonzález, A., Viesca, J.L., García, A., Hadfield, M. (2015). Ionic liquids as an additive in fully formulated wind turbine gearbox oils. Wear, 328-329: 50-63. https://doi.org/10.1016/j.wear.2015.01.041

[33] Anil, P.M., Rajamohan, V. (2017). Influence of surface roughness and ZDDP additive on the friction and wear of reciprocating sliding surfaces at high contact pressures. Industrial Lubrication and Tribology, 69(5): 738-749. https://doi.org/10.1108/ILT-05-2016-0111

[34] Tiago, G., Restolho, J., Forte, A., Colaço, R., Branco, L.C., Saramago, B. (2015). Novel ionic liquids for interfacial and tribological applications. Colloids and Surfaces A: Physicochemical and Engineering Aspects, 472: 1-8. https://doi.org/10.1016/j.colsurfa.2015.02 .030

[35] Otero, I., López, E.R., Reichelt, M., Fernández, J. (2014). Friction and anti-wear properties of two tris (pentafluoroethyl) trifluorophosphate ionic liquids as neat lubricants. Tribology International, 70: 104-111. https://doi.org/10.1016/j.triboint.2013.10.002

[36] Wu, J., Zhu, J., Mu, L., Shi, Y., Dong, Y., Feng, X., Lu, 
X. (2016). High load capacity with ionic liquidlubricated tribological system. Tribology International, 94:

315-322.

https://doi.org/10.1016/j.triboint.2015.08.022

[37] Huang, G., Yu, Q., Cai, M., Zhou, F., Liu, W. (2017). Investigation of the lubricity and antiwear behavior of guanidinium ionic liquids at high temperature. Tribology International, 114:

65-76. https://doi.org/10.1016/j.triboint.2017.04.010

[38] Huang, G., Yu, Q., Cai, M., Zhou, F., Liu, W. (2017). Investigation of the lubricity and antiwear behavior of guanidinium ionic liquids at high temperature. Tribology International, 114: 65-76.

https://doi.org/10.1016/j.apsusc.2014. 12.061

[39] Winer, W.O., Peterson, M.B. (Eds.). (1980). Wear Control Handbook, American Society of Mechanical Engineers, New York.

[40] Ngo, H.L., LeCompte, K., Hargens, L., McEwen, A.B. (2000). Thermal properties of imidazolium ionic liquids. Thermochimica Acta, 357: 97-102. https://doi.org/10.1016/S0040-6031 (00)00373-7 